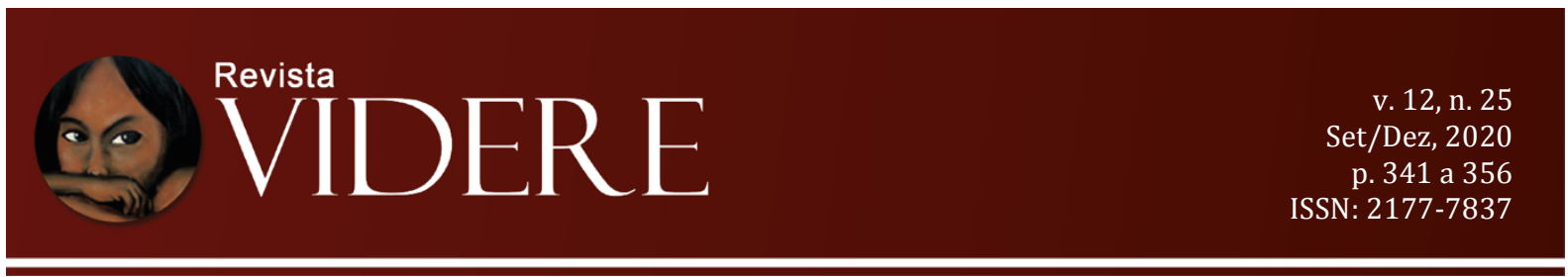

\title{
RELAÇÕES FRONTEIRIÇAS: REFLEXÕES SOBRE POLISSEMIA, DINAMISMO, CONFLITOS E MULTICULTURALISMO
}

\author{
FRONTIER RELATIONS: REFLECTIONS ON POLYSEMIA, DYNAMISM, CONFLICTS \\ AND MULTICULTURALISM
}
RELACIONES FRONTERIZAS: REFLEXONES SOBRE POLISEMIA, DINAMISMO, CONFLICTOS Y MULTICULTURALISMO

Cristina Rezende Eliezer

Doutoranda em Educação (PUC) cristinaeliezer@yahoo.com.br

OrcidID: 0000-0003-2297-2997

Alex Junior Bilhoto Faria

Mestre em Educação (UFLA)

alexbilhoto@gmail.com

OrcidID: 0000-0002-7554-637X

Helena Maria Ferreira

Doutora em Linguística Aplicada (PUC)

helenaferreira@ufla.br

OrcidID: 0000-0002-8749-5426

\begin{abstract}
Resumo: Partindo do pressuposto de que a ciência jurídica é um campo complexo e abrangente, concebido não apenas em sua perspectiva legal, mas, também, como objeto do campo cultural, ultrapassando limites do positivismo jurídico, o presente artigo tem por objetivo discutir as dimensões epistemológicas das relações fronteiriças. Para tal, empreendemos uma reflexão acerca das acepções do termo fronteira, buscando demonstrar que uma visão ampliada das relações fronteiriças no âmbito do Direito pode favorecer a adoção de um compromisso ético no exercício profissional, o cotejamento de doutrinas e jurisprudências, bem como uma compreensão assertiva dos/nos diferentes contextos sociais. $\mathrm{O}$ nosso estudo se constitui por uma pesquisa teórica, organizada em dois momentos. No primeiro momento, problematizamos a constituição polissêmica do termo fronteira, com vistas a demonstrar as potencialidades de sentidos. No segundo momento, abordamos a dimensão multicultural das relações fronteiriças e sua relevância para a ciência jurídica. A partir do estudo empreendido, ressaltamos que as relações fronteiriças podem trazer contribuições substanciais para o campo do Direito, uma vez que é possível ampliar posicionamentos, dinamizar interpretações e promover a justiça, evitando abordagens redutoras e dissociadas da engrenagem social.
\end{abstract}

Palavras-chave: Semântica. Discurso. Polissemia. Multiculturalismo. Fronteira. 


\begin{abstract}
On the assumption that legal science is a complex and comprehensive field, conceived not only in its own legal perspective, but also as an object of the cultural field, surpassing the limits of legal positivism, this article aims to discuss the epistemological dimensions of frontier relations. To this end, a reflection on the meanings of the term frontier has been undertaken, seeking to demonstrate that an expanded view of frontier relations in terms of Law can favor the adoption of an ethical commitment in professional practice, the comparison of doctrines and jurisprudence, as well as an assertive understanding in different social contexts. Our subject is constituted by a theoretical research, organized in two moments. At first, we problematize the polysemic constitution of the term frontier, in order to demonstrate the potential of meanings. As for the second moment, we address the multicultural dimension of frontier relations and its relevance to legal science. From the point of the subject that was undertaken, emphasizing frontier relations can bring substantial contributions to the field of law, since it is possible to expand positions, streamline interpretations and promote justice, avoiding approaches that reduce and dissociate from the social machinery.
\end{abstract}

Keywords: Semantics. Speech. Polysemy. Multiculturalism. Frontier.

Resumen: Partiendo del presupuesto de que la ciencia jurídica es un campo complejo y amplio, concebido no solo en su perspectiva legal, aunque, también, como objecto del campo cultural, sobrepondo límites del positivismo jurídico, el presente artículo tiene por objetivo discutir las dimensiones epistemológicas de las relaciones fronteirizas. Para tal, empreendemos uma reflexión acerca de las acepciones del término frontera, buscando demonstrar que una visión ampliada de las relaciones fronteirizas en el ámbito del Derecho puede favorecer la adoción de un compromiso ético en el ejercicio profisional, el cotejamento deasignaturas y jurisprudencias, biene como una compreensión asertiva de los/en los diferentes contextos sociales. El nuestro estudio se constituye por una investigación teórica, ordenada en dos momentos. En el primeir momento, problematizamos la constituición polisemica del término frontera, con vistas a demonstrar las potencialidades de sentidos. En el segundo momento, abordamos la dimensión multicultural de las relaciones fronteirizas y su relevancia para la ciencia jurídica. A partir del estudio empreendido, resaltamos que las relaciones fronteirizas pueden traer contribuiciones substanciales para el campo del Derecho, una vez que es posible ampliar posicionamientos, dinamizar interpretaciones y promover la justicia, evitando abordagenes reductoras y disociadas del engrenaje social.

Palabras clave: Semántica. Discurso. Polisemia. Multiculturalismo. Frontera.

\title{
1 Introdução
}

O campo jurídico é uma área do conhecimento em constante transformação, que busca compreender as questões sociais e (re)significar modos de agir para a garantia de um equilíbrio no convívio entre o s diferentes sujeitos sociais. Assim, mais que produzir/aplicar leis, o estudo do Direito se constitui como um relevante espaço de reflexão e construção de um pensamento coerente e crítico. Essa concepção do campo parte do pressuposto de que os fenômenos políticos, sociais e econômicos e a inter-relação dos fundamentos filosóficos, axiológicos e teóricos com a sua aplicação prática devem ser dimensionados em uma 
perspectiva interdisciplinar, que possibilita dar conta da complexidade e da abrangência da ciência jurídica.

Nesse sentido, o presente artigo tem por objetivo discutir as dimensões epistemológicas das relações fronteiriças e suas influências para a compreensão do campo jurídico. Para tal, empreendemos uma reflexão acerca das acepções polissêmicas do termo fronteira, buscando demonstrar que uma visão ampliada das relações fronteiriças no âmbito do Direito pode favorecer a adoção de um compromisso ético no/com o exercício profissional, o cotejamento de doutrinas e jurisprudências, bem como uma compreensão assertiva dos/nos diferentes contextos sociais.

O nosso estudo se constitui por uma pesquisa teórica, organizada em dois momentos. No primeiro momento, problematizamos a natureza polissêmica do termo fronteira, com vistas a demonstrar as potencialidades de sentidos. No segundo momento, abordamos a dimensão multicultural das relações fronteiriças e sua relevância para o contexto jurídico. A partir do estudo empreendido, ressaltamos que as relações fronteiriças podem trazer contribuições substanciais para o campo do Direito, uma vez que é possível ampliar posicionamentos, dinamizar interpretações e promover a justiça, evitando abordagens redutoras e dissociadas da engrenagem social e de uma perspectiva interdisciplinar.

\section{Fronteira, polissemia e historicidade}

Certos termos nos remetem a uma multiplicidade de sentidos, no entanto, nem sempre são situados em uma discussão epistemológica que ilumine uma reflexão teórica capaz de sistematizar os efeitos dessa pluralidade. Um exemplo disso é o termo "fronteira". O dicionário eletrônico Michaelis (2020) apresenta, por exemplo, nove acepções para o termo “fronteira", no singular. Tendo em vista que o intuito precípuo deste estudo é a realização de certa exegese sobre o dinamismo fenomenológico das relações fronteiriças, serão reproduzidos, integralmente, os verbetes:

fron $\cdot$ tei $\cdot$ ra

sf

1 Parte que corresponde ao limite extremo de uma terra, área, região etc., a parte limítrofe de um espaço que confina com outro.

2 POR EXT Espaço contíguo a esse limite extremo.

3 Limite, marco ou linha divisória entre duas regiões, dois estados, países etc.

4 POR EXT Marco ou limite extremo de alguma coisa, principalmente de um espaço; termo, fim.

5 FIG Ponto extremo, mais avançado ou mais profundo, de algo de caráter abstrato. 
6 FIG Estado, condição ou situação limite; raia, limiar.

7 FÍS Limite material que separa um sistema físico e sua região externa; separação estabelecida entre um sistema e seu exterior.

8 MAT Conjunto dos pontos situados nas linhas fronteiras de um conjunto qualquer; contorno.

9 MIL, ANT Denominação atribuída a guardas de fronteira ou a expedições militares encarregadas de zelar pelas regiões de fronteiras de países.

A pluralidade de sentidos exposta, obviamente, não esgota as acepções cabíveis ao termo. Se compararmos os verbetes correspondentes em outro Dicionário, possivelmente, outros sentidos poderão ser aludidos e o número acima epigrafado se elevará, culminando em um caso de polissemia.

Orlandi (2000) esclarece que polissemia é a possibilidade de atribuição de múltiplos sentidos para uma mesma enunciação; os sentidos múltiplos estão relacionados à criatividade, que instaura o diferente na linguagem. A polissemia traz consigo a força de ruptura na medida em que o uso pode divergir da produção primeira de sentidos. Tal ruptura ocorreria em função da tensão da relação com o contexto histórico-social; a tensão, portanto, pode criar novas formas e uma multiplicidade de sentidos. Assim, compreender as relações fronteiriças pode propiciar uma compreensão mais ampliada dos discursos, perscrutando sobre a sua as especificidades de um determinado conceito.

Diante do exposto, podemos considerar o posicionamento de Cotanda (2014), que adverte que termos cujos significados são polissêmicos podem representar motivos de ruídos na comunicação. Assim, a polissemia pode ter seus efeitos negativos amplificados quando se trata de termos que possuem status de conceito ou que são utilizados em uma cadeia argumentativa em que se exige uma atenção aos usos da linguagem. $\mathrm{O}$ autor salienta que, de modo frequente, deparamo-nos com evidências de que o emprego da palavra não garante por si só o compartilhamento intersubjetivo de significados, podendo desencadear a produção de sentidos não desejados pelos interlocutores. Por outro lado, granjear um significado unívoco, sem ambiguidades e/ou polissemias, para termos que produzem abstrações expressivas nas Ciências Sociais, nos parece improvável, senão impossível.

A ideia de fronteira, realmente, é inquietante. Aliás, as reflexões acerca da palavra foram ganhando novas acepções, de acordo com o contexto histórico e com as vontades dos sujeitos que a qualificava. De diplomatas a geógrafos e de juristas a historiadores, fato é que sempre foi permeada de fenômenos. Às vezes, um risco no mapa, noutras, um porto com navios. Além do mais, não esqueçamos as lendas. Quantas lendas fronteiriças povoaram o imaginário! Afinal, fronteira une ou separa? 
Hannerz (1997), explanando sobre esse assunto, afirma que o termo evoca duas outras palavras: fluxo e limite. Ressalta que se "fluxo" sugere uma espécie de continuidade e passagem, "limites" têm a ver com descontinuidades e obstáculos; limite pode ser, ainda, uma linha clara de demarcação, em relação à qual uma coisa ou está dentro ou está fora.

Tendo em vista que fronteira, além de remeter ao termo "fluxo", também evoca "limite", Santos (2011) esclarece que as palavras fronteira e limite, não raramente, são empregadas como sendo expressões sinônimas, apesar da redução implicada nesse gesto. No entanto, evidencia que fronteira aparece mais frequentemente associada aos fenômenos espaciais enquanto limite parece estar mais próximo da indicação de fim ou esgotamento de qualquer natureza.

Se limite incute fim, quando analisado sob o viés espacial ou territorial, sendo menos abrangente que fronteira, há, então, uma diferença substancial entre os dois vocábulos. Embora guardem similaridade, não têm o mesmo sentido e indicam direções antagônicas; são independentes e harmônicos entre si.

Machado (1998) esclarece, a esse respeito, que as diferenças entre "limite" e "fronteira" são bastante evidentes, por isso, os termos não são sinônimos, já que fronteira corresponde a "forças centrífugas", que indicam uma direção para fora, ao passo que limites "estão orientados para dentro, forças centrípetas"; "enquanto a fronteira pode ser um fator de integração, [...], o limite é um fator de separação" (p. 41-42).

Observa-se que fronteiras estão mais relacionadas a um trajeto que se direciona para o lado de fora. Noutra margem, os limites estariam orientados para dentro. É como se a fronteira unisse e o limite separasse. No entanto, já que se trata de um conceito que integra vários outros, há também autores que consideram, de forma ampla e desprovida de análises científicas que fronteira é, apenas, linha ou limite. A fuga seria um modo a evitar um entrave conceitual.

Este conceito integra uma série de outros termos, de uma das mais extraordinárias invenções intelectuais do homem, para poder comunicar as suas ideias, levantar suas dúvidas e explicar as suas soluções para os problemas da pesquisa: a linguagem científica. Apenas num sentido mais amplo e, portanto, menos preciso e pouco válido para o campo da ciência, as fronteiras poderiam hoje ser consideradas apenas como linhas ou como limites, separando grupos sociais ou culturas. Isto não é usual entre os pesquisadores que trabalham com a problemática da fronteira, no campo das ciências humanas (KERN, 2016, p. 11). 
Dissertando sobre o mesmo assunto, Águas (2013) esclarece que é possível que a ideia de fronteira encarne na concretude do cimento ou na abstração da metáfora, podendo ser utilizada para explicar o que separa os grupos sociais, mas também o que os une. É possível recorrer ao termo para tratar da divisão entre nações, da globalização, das identidades, da expansão agrícola e de muitos outros assuntos, a partir de diferentes ângulos, muitos deles contraditórios entre si. Portanto, é mesmo preciso ser "gigante" para ver a fronteira na sua multiplicidade, como linhas divisórias de diferenciação espacial, temporal e cultural; as fronteiras distanciam a identidade interna da alteridade externa. Mas, como entre espaços compartilhados, ligam-nas.

O termo "espaço", além de estar relacionado à concretude do lugar, também pode estar interligado às relações de poder. Sobre esse tema, Souza (2003) afirma que, sendo o espaço delimitado por e a partir de relações de poder, o território não se refere somente aos limites político-administrativos estabelecidos por linhas ou marcos divisórios. Está, inclusive, relacionado ao poder de dominação, representado pelos limites políticos, circunscrição e, quiçá, territorialidade.

A territorialidade, de acordo com Haesbaert (2004), além de incorporar uma dimensão mais estritamente política, diz respeito também às relações econômicas e culturais, pois está intimamente ligada ao modo como as pessoas utilizam a terra, como elas próprias se organizam no espaço e como elas dão significado e interpretam o lugar.

Os vieses são muitos. Aliás, viés também é linha. Se, por um lado, a fronteira liga, por outro, divide. São ângulos antagônicos, cujo caminho perpassa pelo concreto chegando ao abstrato. Ou o contrário. Ângulos que remetem às nações e à globalização. Mas, acima de tudo, ângulos que demonstram a multiplicidade, consubstanciada nas divisões não só espaciais, mas culturais e históricas.

A reflexão sobre fronteiras, quando associada aos aspectos históricos, corrobora com a ideia de que os sentidos atribuídos aos termos sofrem influências temporais, já que "cada época entende um texto transmitido de uma maneira peculiar, pois o texto constitui parte do conjunto de uma tradição pela qual cada época tem um interesse objetivo e na qual tenta compreender a si mesma" (JASMIN, 2005, p.30).

Considerando que a história é sempre permeada de conceitos, e que esses só podem ser interpretados com respaldo no seu tempo, Jasmin (2005) explica que é imprescindível que prestemos atenção ao significado dos conceitos diante do recorte de tempo histórico. As ideais do passado devem ser descobertas e interpretadas através do horizonte conceitual que lhes é 
coetâneo e em termos dos usos linguísticos, mutuamente compartilhados e desempenhados pelos atores que participam desses conflitos.

Quando analisamos a produção intelectual de uma sociedade fronteiriça, a ideia de fronteira sempre surge de maneira recorrente nas diversas interpretações sobre a sua própria história. Algumas das citações que indicam a tônica de muitas interpretações são: "somos uma fronteira", "uma fronteira em armas", "uma fronteira movediça", "foi a fronteira que nos deu uma fisionomia histórica", "drama de fronteira". Uma fronteira, entretanto, sempre tem pelo menos duas faces e a oposição fronteiriça, pelo menos dois sentidos (KERN, 1982).

É importante considerar que as ligações entre a realidade histórica e os conceitos podem ser compreendidas sob possibilidades diferentes. Assim se expressou Bentivoglio:

Os liames entre a realidade histórica e os conceitos se dão em meio a quatro possibilidades fundamentais: a realidade e os conceitos permanecem estáveis ao longo do tempo, o conceito e a realidade mudam simultaneamente de modo harmônico, os conceitos mudam, mas a realidade não ou, enfim, a realidade muda, mas os conceitos permanecem os mesmos (BENTIVOGLIO, 2010, p.128).

Voltando à elucidação sobre a importância da análise das fronteiras com respaldo nos aspectos históricos, Mattos (1990 apud ALBUQUERQUE, 2009) salienta que a reflexão sobre as fronteiras nacionais durante o século XIX e primeira metade do século XX foi feita por diplomatas, juristas, geógrafos, historiadores e militares. Os trabalhos estavam determinados, principalmente, em questões acerca de conflitos de limites, tratados de fronteiras, movimentos expansionistas dos Estados nacionais e, sobretudo, redefinições das fronteiras. A referência principal eram os agentes dos Estados e seus movimentos de conquista, expansão, demarcação e garantia do território nacional. A palavra "fronteira" estava associada à dimensão militar, territorial e estatal.

Os estudiosos do tema fronteira no Brasil, quando examinam a literatura pertinente, se deparam com duas concepções de referência. Os geógrafos, desde os anos quarenta, importaram a designação de 'zona pioneira' para nomeá-la, outras vezes referindo-se a ela como 'frente pioneira'. Os antropólogos, por seu lado, sobretudo a partir dos anos cinquenta, definiram essas frentes de deslocamento da população civilizada e das atividades econômicas, de algum modo reguladas pelo mercado, como frentes de expansão (MARTINS, 1997, p. 151-152).

A origem histórica da palavra fronteira, de acordo com Machado (1998), mostra que seu uso não estava associado a nenhum conceito legal e que não era um conceito 
essencialmente político ou intelectual. Nasceu como um fenômeno da vida social espontânea, indicando a margem do mundo habitado. Na medida em que os padrões de civilização foram se desenvolvendo acima do nível de subsistência, as fronteiras entre ecúmenos tornaram-se lugares de comunicação e, por conseguinte, adquiriram um caráter político.

Kern (2016), sobre os aspectos históricos, ressalta que o conceito de fronteira é pouco comum nos dicionários de termos históricos, muito provável por ser concebido por autores que habitam as metrópoles e não nas periferias. Para os pesquisadores fronteiriços, entretanto, adverte que este conceito tem sido primordial para pesquisas históricas sobre os grupos sociais localizados nos limites extremos de territórios contíguos. O conceito de fronteira é utilizado com base em uma escolha deliberada e racional, obtida por intermédio de respostas para os questionários científicos estabelecidos sobre as situações limites, especialmente, nos territórios onde sociedades e culturas diversas se encontram e se confrontam. Esses espaços fronteiriços permitem que sejam ilustradas as trocas culturais, as mútuas influências linguísticas e o lento amadurecimento de sínteses que geram novas identidades fronteiriças; é o chamado dinamismo e multiculturalismo.

A história da geografia das fronteiras, de acordo com Ferrari (2014), nos mostra que, desde a origem e aceitação da palavra na linguagem corrente, fronteira vai adquirir significados diversos e vai responder às necessidades e expectativas dos grupos no tempo e no espaço. Como qualquer outro conceito, o de fronteira também sofreu variações e/ou adaptações, sendo próprio da ciência que, no avanço do conhecimento, sejam buscadas, de forma incessante, respostas mais adequadas para elucidar, em determinados momentos, os fenômenos que nos cercam.

Já Albaret Schulz et al. (2004 apud ÁGUAS, 2013) informam que, na modernidade, o conceito foi associado à noção de soberania. A aparição da linha fronteiriça acompanhou o desenvolvimento da concepção moderna de espaço e participou do aperfeiçoamento da cartografia e das estratégias militares. Com o projeto colonial, a fronteira do Estado foi exportada para além da Europa e impôs-se ao planeta.

Discorrendo sobre essa questão, Águas (2013) complementa que as diferentes concepções de fronteira podem elucidar tendências diferenciadas. Uma definição de fronteira como espaço de interação tenderá a assumir um valor crítico, enquanto concepções de fronteira como espaço de separação vislumbram tendências mais conservadoras. Dessa forma, há um alerta para o uso despretensioso do conceito, já que o termo pode indicar relações de poder estabelecidas no espaço fronteiriço. 
Enfim, tais discussões aqui brevemente apresentadas, propõem, diante não só da polissemia, mas das próprias relações inerentes, uma possibilidade de avaliação por um sentido mais humano e cultural do termo fronteiras.

\section{Dinamismo, conflitos e multiculturalismo}

Ao discorrermos sobre a concepção de fronteira, em uma perspectiva jurídica, partimos do posicionamento de Ferrari (2014), que entende que fronteira possui duas visões científicas: uma relacionada à história política entre Estados nacionais e ao limite de soberania de um poder central e, por outro lado, uma local ou regional, que dispõe sobre as interações entre populações em zonas fronteiriças. Nessas duas visões, fronteira se situa hoje dentro de uma ampla problemática, tornando-se objeto de pesquisas científicas, com inúmeras variáveis de estudos, mas a tendência moderna parece apontar para um contexto mais humano, social e cultural, capaz de nos oferecer uma apreensão mais justa e real das relações fronteiriças. É o dinamismo das relações fronteiriças.

Isso nos remete à noção de multiculturalismo, que não propõe a suplantação das diferenças entre culturas, mas "ampliar ao máximo a consciência de incompletude mútua por intermédio de um diálogo que se desenrola, por assim dizer, com um pé em uma cultura e outro em outra" (SOUSA SANTOS, 2003, p. 444). Nesse sentido, as relações fronteiriças se configuram uma diversidade de culturas.

Para Kern (2016), por intermédio da fronteira, os indivíduos se distinguem e, ao mesmo tempo, se identificam. São nesses espaços que se estabelecem as normas sociais e se definem aqueles que podem participar das sociedades e culturas que ali se identificam. É possível que as sociedades, por exemplo, identifiquem a situação limite, por meio de placas rodoviárias indicativas do término do domínio territorial de um país e do início de outro. As unidades militares situadas de um lado ou de outro desses denominados limites políticos se distinguem umas das outras por seus uniformes, suas insígnias e por suas bandeiras. As sociedades situadas frente a frente, nesses confins, possuem culturas, línguas e identidades diferentes, porém, ao mesmo tempo, interagem continuamente e intercambiam influências, criando sínteses culturais interessantes e inovadoras.

Apesar do multiculturalismo que permeia as sociedades situadas na fronteira, ainda que frente a frente e, embora isso pareça, notadamente, impossível, a linguagem e as identidades diferentes guardam estreita sintonia entre si, posto que as constantes e necessárias interações favoreçam o intercâmbio de influências, sendo um terreno propício ao surgimento 
de inovadoras sínteses culturais. E a reflexão sobre cultura, dentro dos contextos da globalização e transnacionalidade, é necessária e, sobretudo, um dos temas profícuos à porfia.

\begin{abstract}
Nos últimos tempos, em vez de buscarmos a confortadora intimidade da vida provinciana, temos debatido a distância cultural que separa navio e terra firme, e as maneiras de atravessá-la. Fluxo, mobilidade, recombinação e emergência tornaram-se temas favoritos à medida que a globalização e a transnacionalidade passaram a fornecer os contextos para nossa reflexão sobre a cultura. Hoje procuramos locais para testar nossas teorias onde pelo menos alguns dos seus habitantes são crioulos, cosmopolitas ou cyborgs, onde as comunidades são diásporas e as fronteiras na realidade não imobilizam mas, curiosamente, são atravessadas. Freqüentemente é nas regiões fronteiriças que as coisas acontecem, e hibridez e colagem são algumas de nossas expressões preferidas por identificar qualidades nas pessoas e em suas produções (HANNERZ, 1997, p. 7-8).
\end{abstract}

A facilidade da estabilidade e o conforto da vida provinciana não são tão interessantes como deveriam parecer. É justamente a distância cultural existente, metaforicamente, entre o navio e a terra firme que é intrigante. As fronteiras que perpassam as realidades diferentes não são capazes de imobilizar, muito pelo contrário, elas instigam a travessia e a transposição. É a busca pelo outro lado, pelo que há após o risco imaginário ou a linha no mapa. É na fronteira que acontecem as produções enriquecedoras. O debate sobre essa questão evidencia a multidimensionalidade das relações sociais, que evidencia o protagonismo dos sujeitos e a justificam a existência de um ordenamento jurídico aberto às imprevisibilidades.

Lacoste (1988), corroborando com esse entendimento, ensina que vivemos, a partir do momento atual, numa espacialidade diferenciada, composta de uma multiplicidade de representações espaciais, de dimensões muito diversas, que correspondem a toda uma série de práticas e de ideias, mais ou menos dissociadas, porém, interligadas. Quando se trata de fronteiras essa pontuação se sobreleva, uma vez que as relações sociais foram ampliadas a partir do fenômeno da globalização e da disseminação da Internet, que trouxeram impactos para uma reconfiguração dos modos de conceber os pressupostos e a prática jurídica.

Assim sendo, as múltiplas representações espaciais não são dissociadas umas das outras quando há referências fronteiriças. As populações dos dois lados apresentam ideias e práticas que, apesar de distintas, não são completamente apartadas. As trocas culturais e as influências, sobretudo, linguísticas, compõem as identidades fronteiriças. E uma das características interessantes dos jogos de linguagem é o fato de serem jogados por jogadores não equivalentes. 
Os jogos de linguagem existem para serem jogados por jogadores não idênticos, de modo que os mesmos atores usando as mesmas palavras têm de parar e questionar o que querem dizer com elas. As palavras denotam diferentes coisas ao mesmo tempo. O debate a respeito de como elas podem ser usadas para significar, normalmente, responderá às novas experiências, realizando debates sobre os problemas que vêm à tona em seu discurso (POCOCK, 2003).

Se os jogadores não são idênticos e, por analogia, se as populações situadas nos lados opostos da fronteira também não são, os jogos de linguagem possibilitarão novas experiências e debates, além de uma considerável problematização, que também se vê, conforme observado, na palavra "fronteira". Aliás, a fronteira que une, diferente da que separa, repudia os fundamentalismos.

A noção de fronteira que une nega os fundamentalismos: o caráter emancipatório da metáfora manifesta-se nas tendências ao cosmopolitismo ${ }^{1}$ viabilizadas pela proliferação das margens. Essa forma de sociabilidade se abre para a diversidade e também para os riscos e incertezas, do entre lugar fronteiriço (ÁGUAS, 2013).

Se o cosmopolitismo preconiza a universalidade e a extinção das fronteiras nacionais, a cosmopolitização deve ser entendida como uma tarefa, tendo em vista que a globalização mundial, conforme bem salientou Vandenberghe (2011) é

um dado e um fato. A cosmopolitização é um ato e uma tarefa. Se o mundo deve ser mais do que um sistema mundial, unificado por um substrato econômico e tecnológico que atinja o globo, para se tornar um universo, simbolicamente unificado por uma visão do mundo que coexista com outras visões do mundo articuladas entre si através de um diálogo intercultural e de um projeto comum para a humanidade em geral, nós temos que sair do globalismo rumo ao cosmopolitismo. O cosmopolitismo pressupõe uma cosmologia, uma visão englobadora do lugar do gênero humano no universo, e também uma filosofia da história que delineie uma visão normativa de seu destino e de sua unidade na diversidade. Em termos mais especulativos, podemos dizer que o cosmopolitismo representa a verdade da globalização. A cosmopolitização é a globalização an und für sich [em e para si], para falar como Hegel. É a resolução dialética da história mundial na qual a globalização se torna consciente de sua própria alienação em e enquanto sistema mundial autoperpetuador ("globalização an sich" [em si]) e luta para superar sua crise numa nova síntese planetária que preserve suas realizações ao dirigi-las para uma nova direção mais espiritual e mais humana

\footnotetext{
${ }^{1} \cos \cdot \mathrm{mo} \cdot \mathrm{po} \cdot \mathrm{li} \cdot \mathrm{tis} \cdot \mathrm{mo}$ sm

1 Característica ou qualidade do que é cosmopolita.

2 Tendência a observar o estilo de vida dos grandes centros urbanos do mundo.

3 Interesse e afeição por tudo que procede dos grandes centros urbanos do mundo.

4 FILOS Doutrina que prega a universalidade e a extinção das fronteiras nacionais, alegando que a pátria de todos os homens é o Universo. (Dicionário Online Michaelis da Língua Portuguesa, 2020). 
("globalização für uns" [para nós]). Como em todas as teorias dialéticas, são o Weltgeist [espírito do mundo] e a Weltanschauung [visão de mundo] normativa incorporada pelo espírito que fundamentalmente "direcionam" o curso da história, conduzindo-o e dirigindo-o adiante em direção à sua verdade final (p. 85-86).

O universo deve ser, ainda que simbolicamente, unificado. As diferentes visões precisam manter uma coexistência necessária, permitindo que haja articulação, por meio de um diálogo intercultural e, principalmente, por intermédio de um projeto para a humanidade. É a migração do globalismo ao cosmopolitismo. É a busca de uma unidade na diversidade. É granjear uma direção mais humana, apesar de todas as teorias dialéticas.

Friedman (2001) esclarece que, apesar da existência de conquistas políticas, no que tange à teorização das identidades, possibilitadas pela fixação na ideia de diferença, foi possível verificar uma tendência propícia a ocultar o espaço existente nos interstícios dessa mesma diferença, a partir da qual são geradas novas narrativas identitárias.

A ideia é que os interstícios existentes entre as fronteiras se tornem ocultos, de modo que as diferenças gerem novas identidades. Por isso, a palavra fronteira é tão intrigante. Fronteira permite uma troca incessante e frutífera.

A limitação relativa ao espaço imputa comutação. A separação radical se converte em passagem obrigatória, trânsito de uma atividade constante, atividade de trocas assíduas, transferência entre dois meios, duas substâncias. O que até então era a fronteira de uma matéria, o terminal de um material, passa a ser uma via de acesso dissimulada na entidade mais imperceptível. Assim, a aparência das superfícies ignora uma transparência secreta, uma espessura sem espessura, um volume sem volume, uma quantidade imperceptível (VIRILIO, 1999).

Se a fronteira que separa também propicia a união, já que se trata de passagem para uma atividade ininterrupta e para um multiculturalismo constante, as transferências existentes influenciam na capacidade de compreensão do mundo e na transformação do contexto concernente às sociabilidades.

É possível asseverar, segundo Águas (2013), que as narrativas hegemônicas moldam a maneira moderna de compreender o mundo. É por essa razão que o esbatimento dessas barreiras, consubstanciadas na transformação, tanto no campo das sociabilidades quanto no relativo às fronteiras, se trata de um processo emancipatório. A fronteira como frente é o limite em expansão. É onde, em determinado tempo, se dá o avanço unilateral de um agente transformador sobre o espaço, o que implica a existência de um território, ainda que metafórico. A fronteira não é uma linha inerte, está sempre em movimento. É uma caminhada 
rumo ao que está para além dela. Quando esse movimento termina, a fronteira como frente transforma-se em fronteira que separa.

As zonas territoriais se interpenetram e se mesclam, de tal sorte que a hegemonia dos territórios-zona estatais, que marcaram a imensa colcha de retalhos política, pretensamente uniterritorial, no sentido de só admitir a forma estatal de controle políticoterritorial do mundo moderno, vê-se obrigada, hoje, a conviver com novos circuitos de poder. Esses desenham complexas territorialidades, em geral na forma de territórios-rede (HAESBAERT, 2004).

Apesar de as zonas territoriais ensejarem um multifacetado sistema político, o que possibilita um controle estatal mais efetivo, fomentando o exercício do poder, é forçoso reconhecer que o espaço entre os territórios gera um enriquecimento mútuo, já que várias culturas partilham, em algum momento, certo espaço.

Tais discussões, segundo Águas (2013), oferecem pistas da complexidade do debate em torno da questão da alteridade. Assim, a palavra diálogo, tão desgastada pelo uso corrente, exige bem mais do que a abstrata conexão entre interlocutores, situados em lados opostos. Os sujeitos, simultaneamente, produtores de sentido, precisam de se deslocar para o entre lugar fronteiriço, despindo-se do conforto das relações de poder, já cristalizadas, para se aventurarem no território instável e surpreendente da interseção de mundos.

Isto posto, podemos considerar que é no/pelo diálogo que os sentidos são produzidos, desse modo, ao abordamos a natureza polissêmica do termo fronteira é necessário que esse termo, no âmbito jurídico, seja pluralizado - fronteiras - em função da diversidade de sentidos que o termo pode assumir. Essa questão exemplifica a constatação de Diniz (2009, p. 171172), que ressalta que "a textura aberta das palavras da lei, a ambiguidade e vagueza das expressões legais viabilizam a redefinição dos sentidos normativos pela ciência jurídica e a adoção de uma das alternativas de decisão pela autoridade ou juiz ao aplicar o direito." Assim, se considerarmos que o campo do Direito se constitui na/pela linguagem, ou seja, “a justiça não pode ser construída fora da linguagem" (ALMEIDA; BITTAR, 2012, p. 488), entendemos que o Direito é, assim considerado, em sua teoria, fato interpretativo que depende, sobremaneira, de questões históricas, sociais e linguísticas. Essa concepção imputa ao campo uma reflexão responsável sobre os sentidos do termo fronteira(s), tanto no âmbito histórico-político-espacial, quanto no âmbito da própria área, que apresenta, por excelência, relações fronteiriças entre as diferentes subáreas do Direito e articulações com outros campos do conhecimento. 


\section{Conclusão}

Neste artigo, foi elaborada uma discussão a respeito da multiplicidade de sentidos do termo fronteira(s), as suas relações discursivas, históricas e culturais. Nessa perspectiva, buscou-se apresentar uma compilação de autores que analisam o tema em pauta, buscando caracterizar a natureza complexa dos sentidos produzidos pelos diferentes estudos acerca da dimensão multicultural das relações fronteiriças. Essa discussão poderá contribuir para o campo jurídico, que lida com o conceito em diferentes contextos discursivos. Atentar-se para a natureza polissêmica do termo poderá promover uma ampliação do conceito no âmbito da ciência jurídica, o que permitirá uma qualificação dos posicionamentos por parte do profissional do Direito, bem como dinamizar interpretações e promover a justiça, evitando abordagens redutoras e dissociadas da engrenagem social.

Conforme demonstrado ao longo do artigo, uma análise do termo pode possibilitar uma visão mais crítica não somente do conceito, mas também dos modos de organização e de funcionamento dos discursos (técnica) que organizam o campo do Direito.

Assim, o termo fronteira, então, pode ser redimensionado, deslocando de um mero termo e se transformando em um conceito complexo e abrangente - separa, aparta, junta, estabelece limites, fluxos, trocas culturais e diálogos. Denota partilha, poder, divisão, expansão, aliança, divisa, marco, risco, desenho, processo, extremidade, ponta. Evidencia globalização, nação, descontinuidade, transgressão, ângulo, distância, espaço, identidade, dinamismo, direção, raia, borda, confim, soberania, demarcação, frente, início, fim.

A partir desse conceito se vê interpretação, imersão, universalização, problematização, interseção, movimento, criação, produção, segmentação, união. Por ele, pode se inferir inclusão, socialização, emancipação, discussão, tensão, articulação, aproximação, tradução, tradição, ação, indagação. E, de tão fascinante, inquietante e complexo o termo, ousada e inócua seria a desconsideração de sua natureza polissêmica e seus efeitos na consolidação de uma teoria do Direito que se pauta na multiculturalidade.

\section{Referências}

ÁGUAS, C. L. P. A tripla face da fronteira: reflexões sobre o dinamismo das relações fronteiriças a partir de três modelos de análise. Fórum Sociológico [Online], 23 | 2013, posto online no dia 09 janeiro 2014. Disponível em: < https://journals.openedition.org/sociologico/842>. Acesso em: 25 fev. 2020.

ALBUQUERQUE, J. L. C. A dinâmica das fronteiras: deslocamento e circulação dos "brasiguaios" entre os limites nacionais. Horiz. antropol. vol.15 no.31 Porto Alegre Jan./Jun. 
2009. Disponível em: < http://www.scielo.br/scielo.php?script=sci_arttext\&pid=S010471832009000100006>. Acesso em: 01 março 2020.

ALMEIDA, G. A. de; BITTAR, Eduardo C. B. Curso de filosofia do direito. 10. ed., São Paulo: Atlas, 2012.

BENTIVOGLIO, J. A história conceitual de Reinhart Koselleck. Dimensões, vol. 24, 2010, p. 114-134. Disponível em: < file://C:/Users/adiministrador/Downloads/2526Texto\%20do\%20artigo-3946-1-10-20120307\%20(1).pdf>. Acesso em: 25 fev. 2020.

COTANDA, F. C. A polissemia dos conceitos e suas implicações para a sociologia: os usos do termo "sistema". Disponível em: < http://www.scielo.br/pdf/es/v35n128/0101-7330es-35-128-00829.pdf>. Acesso em: 01 março 2020.

Dicionário Michaelis da Língua Portuguesa (2020). Fronteira.

[2020]. Disponível em: < https://michaelis.uol.com.br/moderno-portugues/busca/portuguesbrasileiro/fronteira/ >. Acesso em: 26 fev. 2020.

DINIZ, M. H. Compêndio de Introdução à Ciência do Direito: Introdução à Teoria Geral do Direito, à Filosofia do direito, à Sociologia Jurídica e à Lógica jurídica. Norma jurídica e Aplicação do Direito. 20. ed. São Paulo: Saraiva, 2009.

FERRARI, M. As noções de fronteira em Geografia. Unioeste, v. 9, n. 10, 2014. Disponível em: < http://e-revista.unioeste.br/index.php/pgeografica/article/viewFile/10161/7550>. Acesso em: 29 fev. 2020.

FRIEDMAN, S. O falar da fronteira, o hibridismo e a performatividade: teoria da cultura e identidade nos espaços intersticiais da diferença. Revista Crítica de Ciências Sociais, 61, 2001, p. 5-28.

HAESBAERT, R. (2004). Dos múltiplos territórios à multiterritorialidade. In Anais do I Seminário Nacional sobre Múltiplas Territorialidades. Porto Alegre: Programa de Pósgraduação em Geografia da UFRGS. Disponível em: < http://www.ufrgs.br/petgea/Artigo/rh.pdf>. Acesso em: 06 março 2020.

HANNERZ, U. Fluxos, fronteiras, híbridos: palavras-chave da antropologia transnacional. Mana, 3(1):7-39, 1997, Disponível em: < http://www.scielo.br/scielo.php?script=sci_arttext\&pid=S0104-93131997000100001>. Acesso em: 06 março 2020.

JASMIN, M. G. História dos conceitos e teoria política e social: referências preliminares. Disponível em: http://www.scielo.br/scielo.php?pid=S010269092005000100002\&script=sci_abstract\&tlng=pt>. Acesso em: 29 fev. 2020.

KERN, A. A. Fronteira/fronteiras: conceito polissêmico, realidades complexas. Disponível em: < https://periodicos.unemat.br/index.php/historiaediversidade/article/view/1617 >. Acesso em: 01 março 2020.

Missões: uma utopia política. Porto Alegre: Mercado Aberto, 1982. 
LACOSTE, Y. A Geografia: isso serve, em primeiro lugar, para fazer a guerra. Campinas: Papirus, 1988.

MACHADO, L. O. Limites, Fronteiras, Redes. In: STROHAECKER, Tânia Marques. et al. (Org.). Fronteiras e Espaço Global. Porto Alegre: AGB-Seção Porto Alegre, 1998.

MARQUES, M. H. D. Iniciação à Semântica. 7. ed. atual. São Paulo: Zahar, 2011. 180 p.

MARTINS, J. S. de. Fronteira. A degradação do outro nos confins do humano. São Paulo: Hucitec, 1997.

ORLANDI, E. P. Análise do discurso: princípios e procedimentos. Campinas: Pontes, 2000.

POCOCK, J. G. Linguagens do ideário político. São Paulo: Edusp, 2003.

SANTOS, C. R. S. Sobre limites e fronteiras: a reprodutibilidade do estoque territorial para os fins da acumulação capitalista. Disponível em: < https://journals.openedition.org/confins/7081?lang=pt>. Acesso em: 08 março 2020.

SOUSA SANTOS, B. de. Reconhecer para libertar: os caminhos do cosmopolitismo multicultural. Rio de Janeiro: Civilização Brasileira. 2003.

SOUZA, M. J. L. O território: sobre espaço e poder, autonomia e desenvolvimento. In I. E. Castro, \& R. L. Corrêa (Eds.), Geografia: conceitos e temas. Rio de Janeiro: Bertrand Brasil, 2003.

VANDENBERGHE, F. Um estado para o cosmopolitismo. Novos estud. - CEBRAP, n. 90, São Paulo, July/2011, p. 85-101. Disponível em: < http://www.scielo.br/scielo.php?script=sci_arttext\&pid=S0101-33002011000200007>. Acesso em: 05 março 2020.

VIRILIO, P. O espaço crítico. Rio de Janeiro: Ed. 34, 1999.

Data de recebimento: 13.05 .2020

Data de aprovação: 18.09.2020 